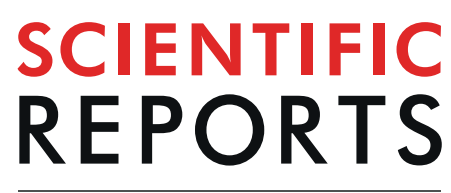

natureresearch

Check for updates

\title{
The endocast of the Night Parrot (Pezoporus occidentalis) reveals insights into its sensory ecology and the evolution of nocturnality in birds
}

\author{
Andrew N. Iwaniuk ${ }^{1 凶}$, Aubrey R. Keirnan ${ }^{2}$, Heather Janetzki ${ }^{3}$, Karine Mardon $^{4}$, \\ Stephen Murphy ${ }^{5}$, Nicholas P. Leseberg ${ }^{5}$ \& Vera Weisbecker ${ }^{2,6 \bowtie}$
}

The Night Parrot (Pezoporus occidentalis) is a rare, nocturnal parrot species that has largely escaped scientific investigation due to its behaviour and habitat preferences. Recent field studies have revealed some insights into Night Parrot behaviour, but nothing is known of its sensory abilities. Here, we used $\mu C T$ scans of an intact Night Parrot specimen to determine if its visual system shares similarities with other nocturnal species. The endocast of the Night Parrot revealed relatively small optic lobes and optic foramina, especially compared with closely related grass parakeets, but no apparent differences in orbit dimensions. Our data suggests that the Night Parrot likely has lower visual acuity than most other parrots, including its congener, the Eastern Ground Parrot (P. wallicus). We propose that the visual system of the Night Parrot might represent a compromise between the need to see under low light conditions and the visual acuity required to detect predators, forage, and fly. Based on the endocast and optic foramen measurements, the Night Parrot fits into a common pattern of decreased retinal input to the optic lobes in birds that should be explored more thoroughly in extant and extinct species.

The Night Parrot (Pezoporus occidentalis) is considered to be one of the world's most elusive birds ${ }^{1}$. It is a small $(100 \mathrm{~g})$, highly cryptic, nocturnal parrot that lives only in the arid interior of Australia. Only 25 scientific specimens were collected between 1845 and around 1875, after which confirmed reports of living birds were absent for more than a century, despite an enormous potential range covering the majority of interior Australia ${ }^{2}$ and intense search efforts by several expeditions ${ }^{1}$. In 1990 and 2006, individual Night Parrot bodies were discovered ${ }^{3,4}$, but it was not until 2013 that photos of live birds and the discovery of a population in southwest Queensland enabled the first scientific study of this species ${ }^{5}$. Prior to 2013, all that was known about Night Parrot behaviour and ecology was based on anecdotal reports or inference ${ }^{1}$. The recent efforts of several researchers have since yielded data on Night Parrot movements ${ }^{6}$, vocalizations $s^{7}$, breeding behaviour ${ }^{8}$, a better understanding of habitat and dietary requirements ${ }^{2,6}$ and new populations discovered elsewhere in Australia ${ }^{1,9}$. Understanding more about the behaviour and ecology of this unique species is critical for species management throughout their range ${ }^{1,2}$, but the highly elusive behaviour of Night Parrots presents a major challenge to filling in knowledge gaps based on fieldwork alone.

One of the characteristic features of the Night Parrot is nocturnality. Adopting a nocturnal lifestyle is generally associated with substantial changes in eye and brain morphology in birds $\mathrm{s}^{10-12}$. In some species, like owls and nightjars, the eye becomes enlarged, retinal anatomy changes in order to capture as many photons as possible, and visual processing areas in the brain are expanded ${ }^{11,12}$. In other species, however, the dependence on vision decreases in favour of using other senses, such as hearing, touch and/or smell, and the eyes and visual regions

${ }^{1}$ Department of Neuroscience, University of Lethbridge, Lethbridge, AB, Canada. ${ }^{2}$ School of Biological Sciences, University of Queensland, St. Lucia, QLD, Australia. ${ }^{3}$ Queensland Museum, South Brisbane, QLD, Australia. ${ }^{4}$ Centre for Advanced Imaging, University of Queensland, St. Lucia, QLD, Australia. ${ }^{5}$ School of Earth and Environmental Sciences, University of Queensland, St. Lucia, OLD, Australia. ${ }^{6}$ College of Science and Engineering, Flinders University, GPO 2100, Adelaide, SA, Australia. ${ }^{\circledR e}$-mail: andrew.iwaniuk@uleth.ca; vera.weisbecker@flinders.edu.au 

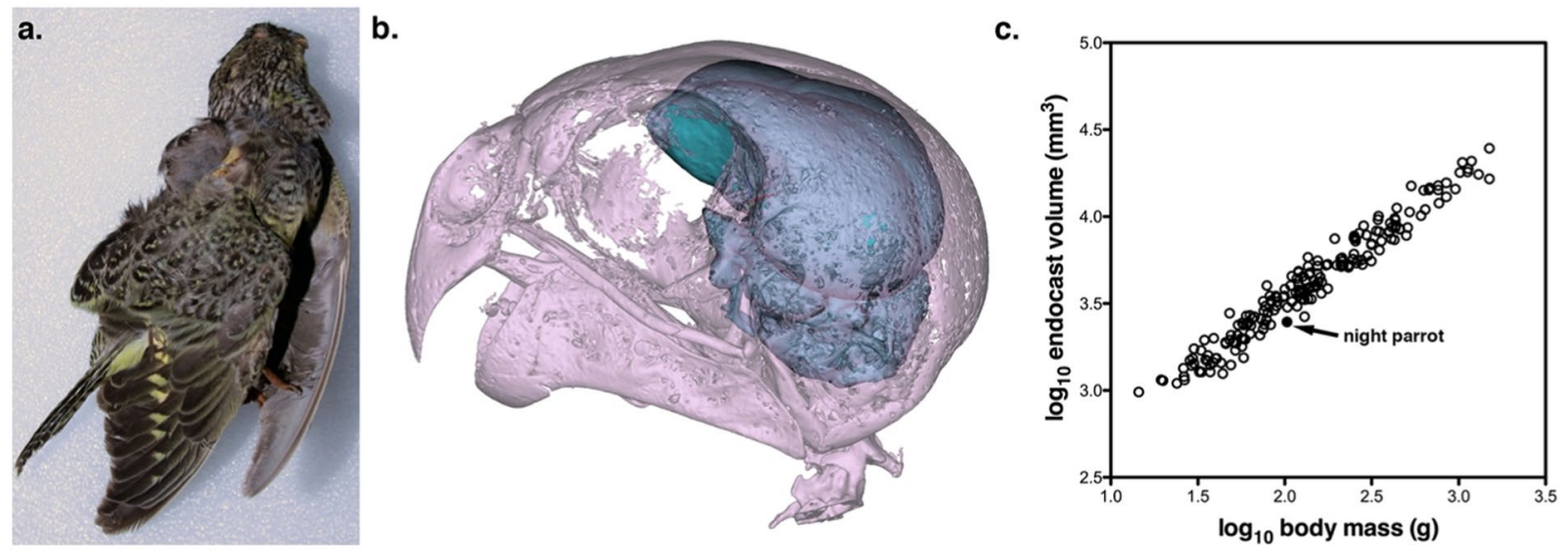

Figure 1. (a) A photo of the Night Parrot (Pezoporus occidentalis) specimen scanned in this study (QM O.29055). (b) The digitally reconstructed skull and endocast of the same specimen is shown. (c) A logtransformed scatterplot of endocranial volume plotted against body mass for 180 parrot species as well as the value obtained for the Night Parrot based on the reconstructed endocast.

of the brain become smaller ${ }^{13-15}$. In the only other nocturnal parrot, the Kakapo (Strigops habroptilus), eye size and shape do not differ from diurnal parrots, but the optic tectum, the primary target of retinal ganglion cells, is greatly reduced in size ${ }^{16}$. The shrinkage of the Kakapo optic tectum coincides with a decrease in size of the optic foramen, which houses the optic nerve, as well as fewer retinal ganglion cells ${ }^{16}$. These anatomical changes result in the Kakapo possessing a visual system with a greater ability to capture photons under low light (higher sensitivity), but a relatively poor ability to discriminate among visual stimuli (lower acuity) compared to diurnal par$\operatorname{rots}^{17}$. Assessing whether the Night Parrot shares a similar visual system to the Kakapo would yield new insights into Night Parrot behaviour, including a better understanding of how they perceive their habitat.

Detailed study of the Night Parrot eye and brain anatomy is not possible due to the extremely limited number of living individuals and lack of fluid preserved museum specimens. However, much information regarding the Night Parrot's visual system can be gleaned from the skull. For example, the optic foramen is well defined in parrots $^{18}$ and reflects optic nerve size ${ }^{16,18}$ and orbital measurements can approximate eye size ${ }^{19}$. Digital endocasts (three dimensional reconstructions of the brain based on $\mu \mathrm{CT}$ scanning of skulls) have also been useful in assessing the sensory ecology of extinct birds ${ }^{20-23}$. In particular, the surface area of the optic lobes reflects the volume of the underlying optic tectum ${ }^{24}$, the midbrain region that receives the majority of retinal projections in birds $\mathrm{s}^{25}$. The optic tectum is also the region that undergoes the greatest reduction in size in other nocturnal birds ${ }^{15,21,26}$, including the Kakapo ${ }^{16}$. Thus, the relative size of the optic foramen, orbits, and optic lobes of the Night Parrot could provide insights into its visual abilities.

Here, we used $\mu \mathrm{CT}$ scans of the only Night Parrot skull known to be intact ${ }^{3}$ (Fig. 1a) to quantify the dimensions of the orbits, optic foramen and optic lobes in comparison with other parrot species. Specifically, we predicted that the Night Parrot would have reduced optic lobes and smaller optic foramina, similar to the Kakapo ${ }^{16}$. However, we expected a reduction of lesser magnitude than what was found in the Kakapo because Night Parrots fly considerable distances between roosting and feeding areas ${ }^{6}$, probably making them more dependent on vision $^{27}$.

\section{Results}

The $\mu$ CT scans of the Night Parrot specimen (Fig. 1a) revealed some fragmentary material on the outside of the skull, but the braincase and orbits were entirely intact, allowing us to complete measurements of both the orbits and the endocast (Fig. 1b). Overall, the endocast had a volume of $2,478.07 \mathrm{~mm}^{2}$, which relative to body mass is typical of other small parrots (Fig. 1c) and similar to that of the Eastern Ground Parrot (Pezoporus wallicus). In terms of morphology, however, the optic lobes of the Night Parrot (Fig. 2a) appeared to be unusually small (Fig. 2b,c), especially compared with its congener and closest relative within the sample, the Eastern Ground Parrot (Fig. 2d-f), and the Bourke's Parrot (Neopsephotus bourkii, Fig. $2 \mathrm{~g}-\mathrm{i}$ ), a closely related grass parakeet ${ }^{28}$ that lives in similar habitat to the Night Parrot and is often active at dusk ${ }^{29,30}$.

Compared with total endocast surface area, the Night Parrot had the smallest optic lobes of any of the species we examined (Fig. 3a,b). Although the Purple-crowned Lorikeet (Glosspsitta porphyrocephala) also has small optic lobes, when expressed as a percentage of total endocast surface area, the Night Parrot had the lowest value (Fig. 3b). More importantly, the relative size of the Night Parrot's optic lobes contrasts greatly with that of its relatives, the grass parakeets (Neophema, Neopsephotus), and its congener the Eastern Ground Parrot, which had the largest optic lobes relative to endocast surface area (Fig. 3a,b). As shown in Fig. 3c, the optic lobes of the Night Parrot falls outside of the $95 \%$ interval of our phylogenetically informed posterior probability distributions. In fact, it exceeds the $99 \%$ interval, indicating that the surface area of the Night Parrot's optic lobes is far below that predicted by its total endocast surface area.

The Night Parrot also had the smallest optic foramen relative to endocast volume (Fig. 3d). In fact, the optic foramen of the Night Parrot was similar in absolute size to that of the Budgerigar (Melopsittacus undulatus), 


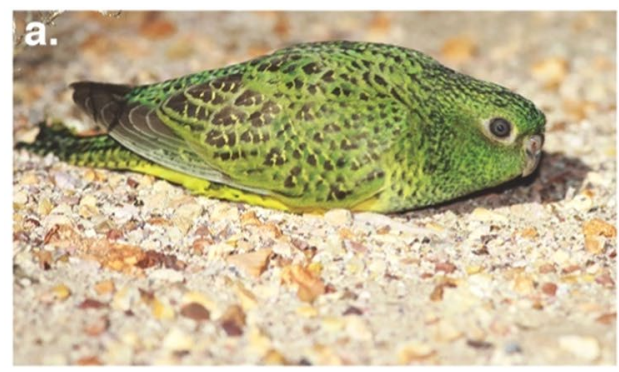

b.
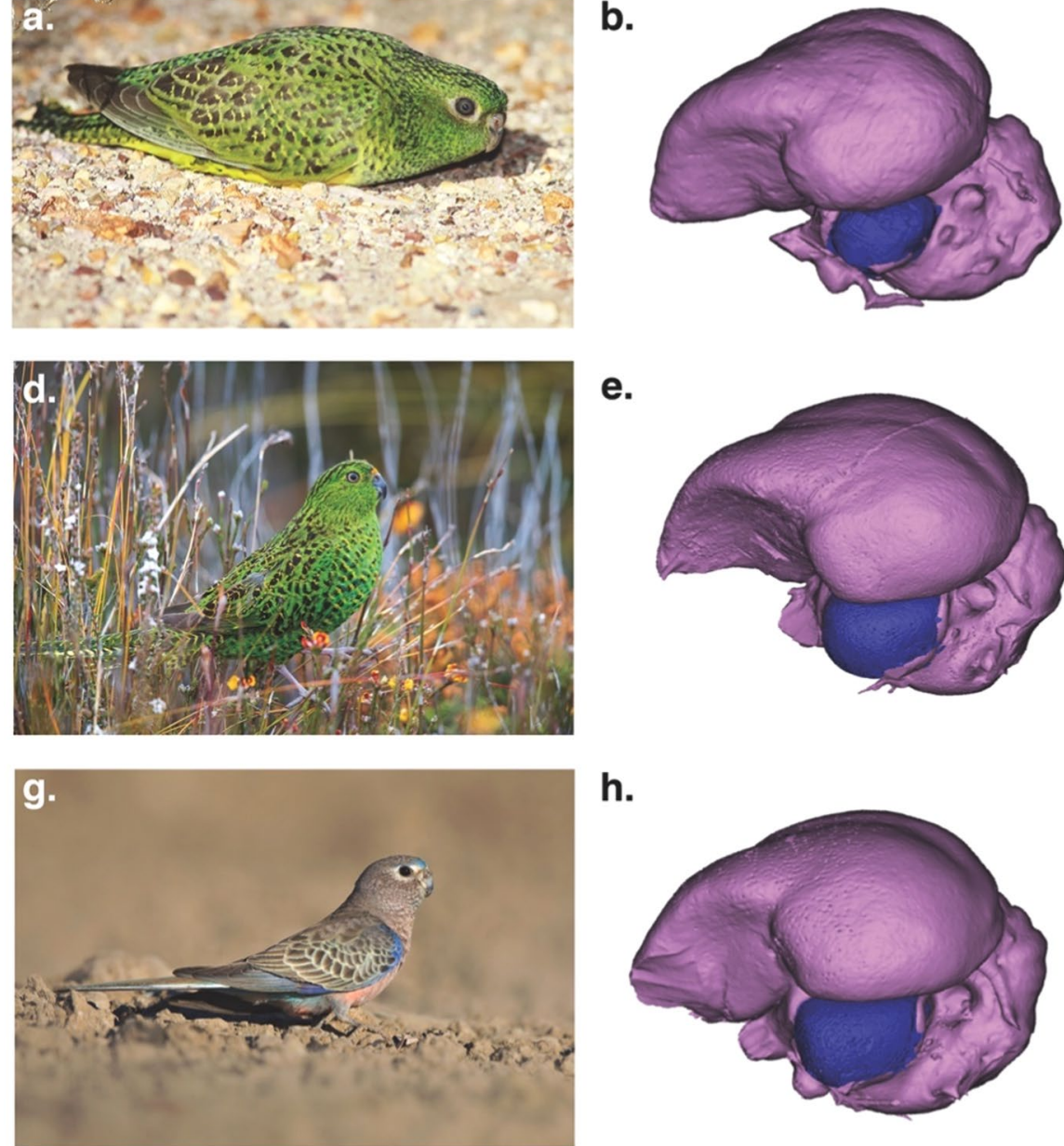

e.

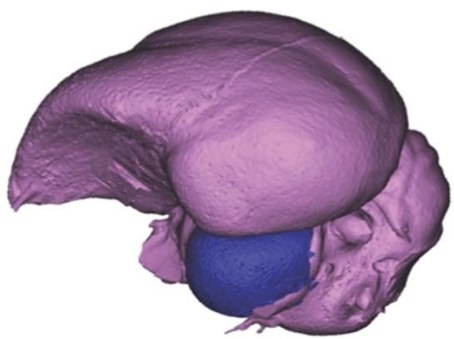

h.

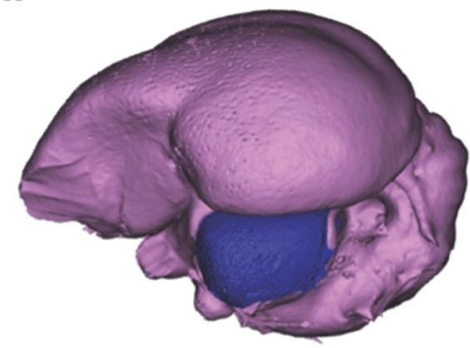

C.

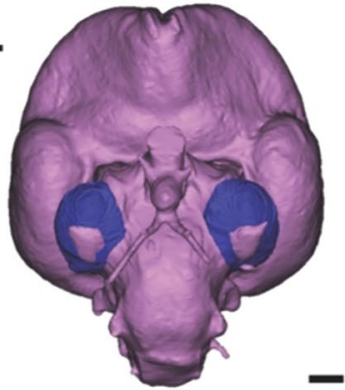

f.

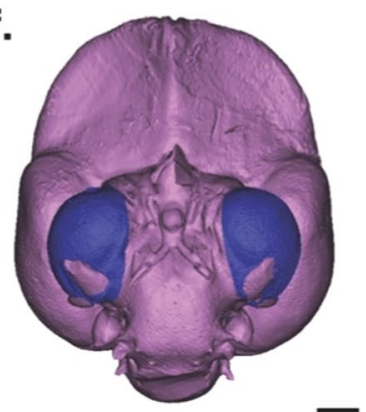

i.

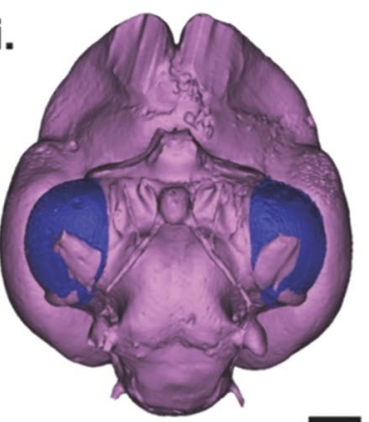

Figure 2. (a) A rare photo of a live Night Parrot (Pezoporus occidentalis) taken by S. Murphy; (b) Lateral view of the Night Parrot endocast with the optic lobe shown in blue; (c) Ventral view of the Night Parrot endocast; (d) A photo of the diurnal Eastern Ground Parrot (Pezoporus wallicus) provided by L. Ross; (e) Lateral view of the Ground Parrot endocast with the optic lobe shown in blue; (f) Ventral view of the Ground Parrot endocast; (g) a photo of the crespuscularly active Bourke's Parrot (Neopsephotus bourkii) provided by D. Paton; (h) lateral view of the Bourke's Parrot endocast with the optic lobe shown in blue; and (i) ventral view of the Bourke's Parrot endocast. On each endocast, the optic lobes are shown in blue. All scale bars $=2 \mathrm{~mm}$.

a species with an endocast volume 2/3 that of the Night Parrot. At the other end of the spectrum, the Eastern Ground Parrot had an optic foramen that was almost 2x that of the Night Parrot even though they share similar endocast volumes (Fig. 3d). The relatively small size of the Night Parrot's optic foramen is also supported by the posterior probability distribution (Fig. 3e).

Unlike the optic lobes and optic foramen, the Night Parrot did not differ in relative orbit area or depth from other parrots (Fig. 3f-i). Although the Ground Parrot did appear to have enlarged orbit area, relative to endocast volume (Fig. 3g), it did not fall outside of the 95\% credible interval (Fig. 3h).

\section{Discussion}

Overall, the Night Parrot has undergone a decrease in relative optic lobe size, at least compared with the closely related grass parakeets, and a decrease in relative optic foramen diameter compared with all other parrots examined. This indicates that the Night Parrot has evolved significant changes in its visual system anatomy, likely in response to its nocturnal activity. Although our conclusions are based on a single Night Parrot specimen, this is one of the rarest species in ornithological collections worldwide ${ }^{1,31}$. No osteological specimens appear to exist $t^{1,3,31}$ and the preparation of study skins involves damage to or removal of the skull ${ }^{32}$. The 'mummified' specimen ${ }^{3}$ is therefore the only Night Parrot specimen known to have an intact skull. Further, for species in which we measured three specimens, intraspecific coefficients of variation were 0.06-0.11 across the optic lobe and optic foramen measurements, suggesting that intraspecific variation is relatively low. If the Night Parrot's optic lobe area and optic foramen diameter are underestimated by $11 \%$, the observed values would still fall outside of the $95 \%$ credibility intervals in Fig. 3c,e. Thus, based upon the available data, we are reasonably confident that the Night Parrot has undergone reductions in the optic lobes and optic foramen, especially in comparison to the Eastern Ground Parrot and other grass parakeets. 

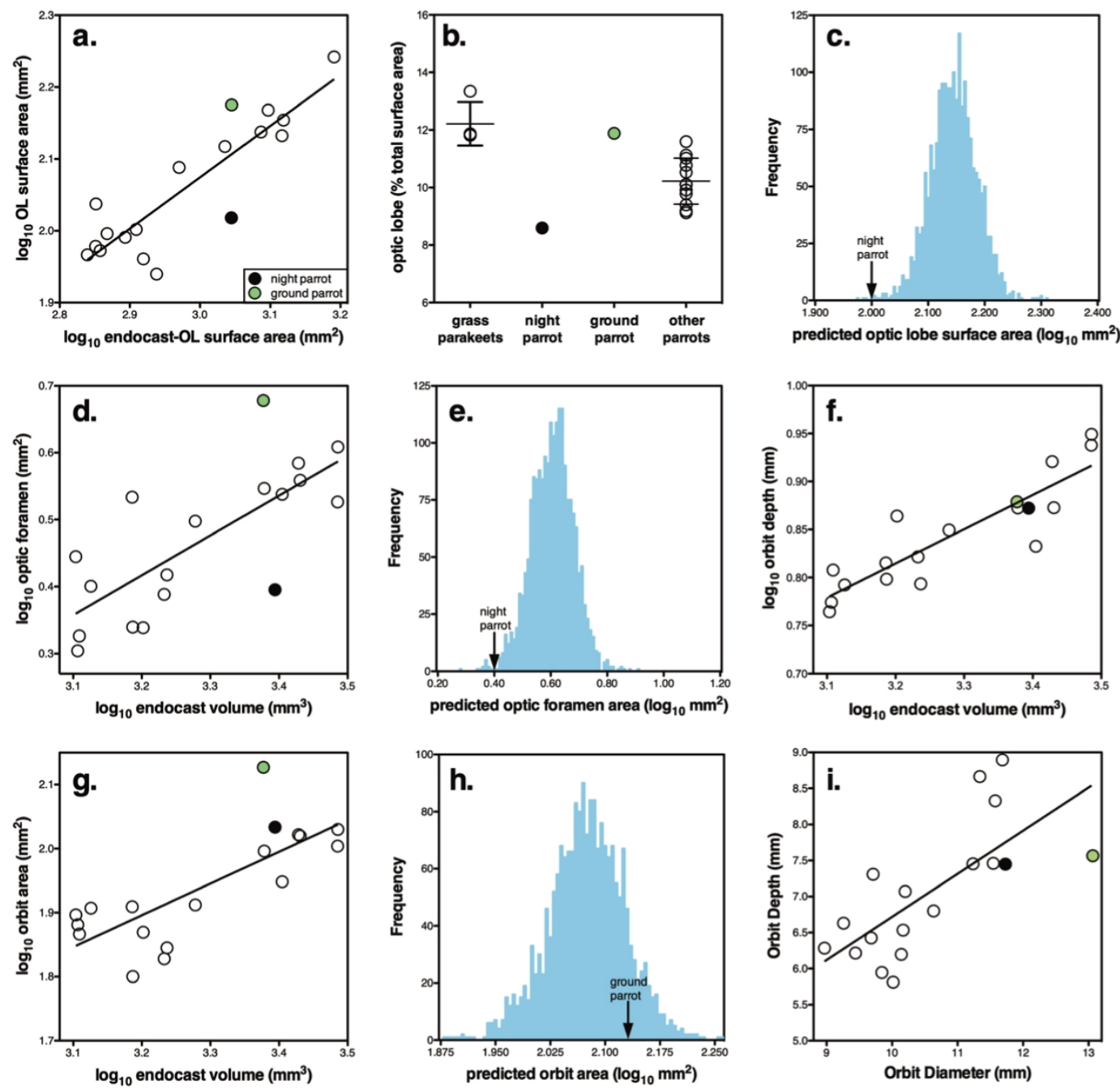

Figure 3. Scatterplots of the quantitative measurements of the skulls and endocasts of the 18 parrot species examined, and accompanying posterior probability distributions. In all scatterplots, the Night Parrot (Pezoporus occidentalis) is shown in black, the Ground Parrot (Pezoporus wallicus) in green and all other species in white. The solid lines indicate the least-squares linear regression lines. The arrows in the posterior probability distributions indicate the observed values of individual species. The plots are as follows: (a) log-transformed optic lobe surface area plotted against endocast surface area minus optic lobe surface area; (b) optic lobe surface area expressed as a percentage of endocast surface area; (c) the posterior probability distribution of the predicted surface area of the optic lobes of the Night Parrot based on phylogeny and allometric relationship with endocast-optic lobe surface area; (d) log-transformed optic foramen area plotted against endocast volume; (e) the posterior probability distribution of the predicted optic foramen area of the Night Parrot based on phylogeny and allometric relationship with endocast volume; (f) log-transformed orbit depth plotted against endocast volume; (g) log-transformed orbit area plotted against endocast volume; (h) the posterior probability distribution of the predicted orbit area of the Ground Parrot based on phylogeny and allometric relationship with endocast volume; and (i) orbit depth plotted against orbit diameter. Note that in (b), the grass parakeets (Neophema, Neopsephotus) are shown separately to help illustrate the difference between the Night Parrot and other members of the tribe Pezoporini.

Despite the reductions in optic lobes and foramina, the Night Parrot did not differ in orbit size from the other species examined. Eye shape, corneal diameter and retinal morphology are often better predictors of low light vision than eye size $e^{10,18,19}$. For example, the nocturnal Kakapo does not differ from other parrots in eye size or shape, but does have a higher density of photoreceptors and fewer retinal ganglion cells ${ }^{16}$. Currently, it is not possible to estimate photoreceptor density in the Night Parrot because a fluid preserved specimen does not exist and capturing one to preserve appropriately is not a viable option. However, the optic nerve is comprised primarily of retinal ganglion cell axons and the size of the optic foramen closely approximates that of the optic nerve in most birds, including parrots ${ }^{16,18}$. The relatively small optic foramina of the Night Parrot therefore reflects smaller optic nerves and, by extension, fewer retinal ganglion cells in the retina. If this assumption is correct, the Night Parrot likely has lower visual acuity than the other parrot species examined because the spatial resolving power of the eye is a product of retinal ganglion cell density and eye $\operatorname{size}^{33}$. 


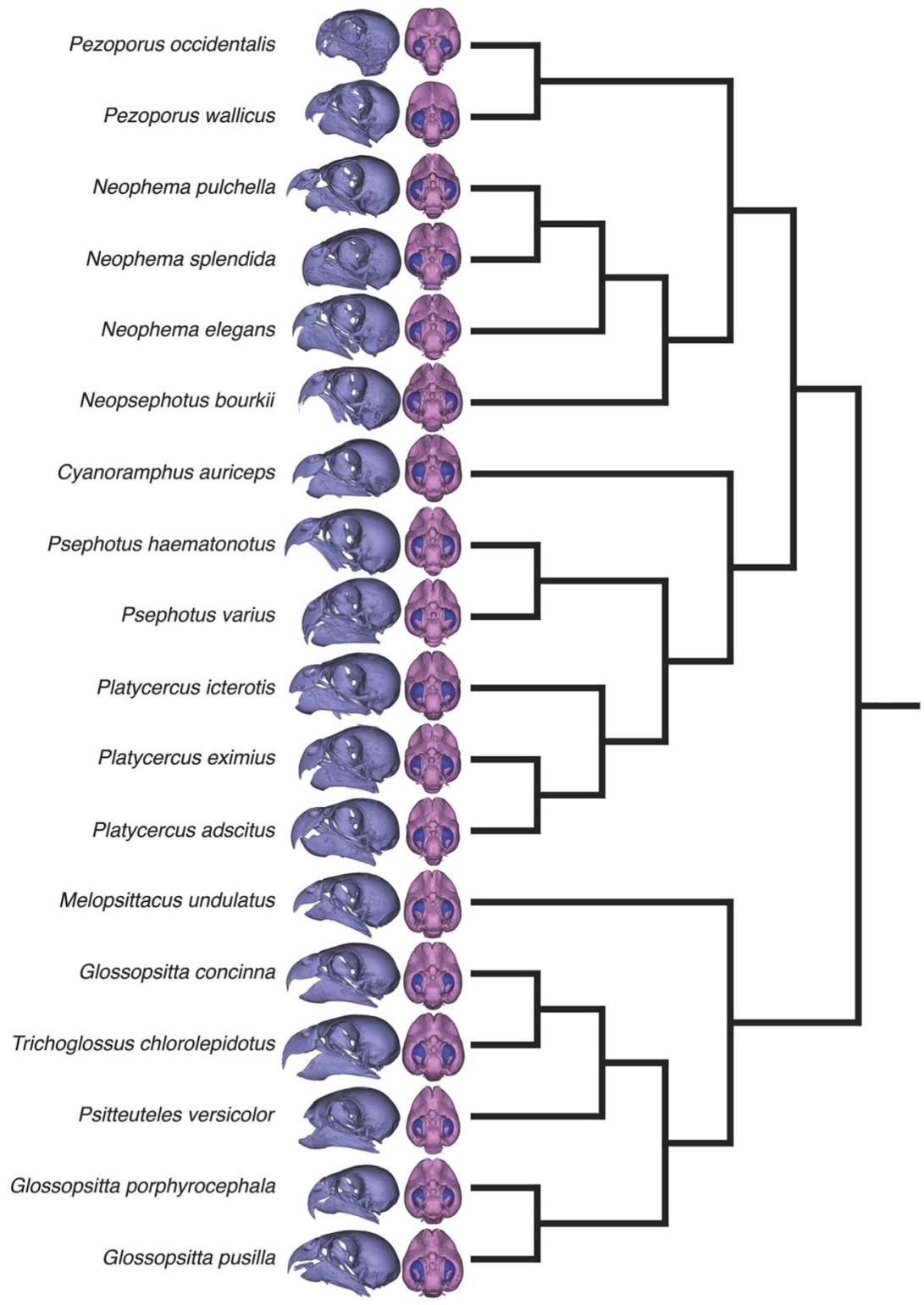

Figure 4. A phylogeny of the 18 parrot species examined in this study. The phylogeny was compiled from recent studies ${ }^{28,53}$. For each species, a digital reconstruction of the skull and a ventral view of the endocast is provided, with the optic lobes shown in blue. Note that the skulls and endocasts are not to scale.

Corroborating support for fewer retinal ganglion cells in the Night Parrot is provided by the reduced optic lobes. The optic tectum receives the majority of the retinal efferents in most birds ${ }^{25}$ and species with fewer retinal ganglion cells also have relatively small optic tectum volumes ${ }^{16,26,34}$. Although the optic lobes house more than just the optic tectum, there is a strong correlation between optic tectum volume and the surface of the optic lobes $^{24}$. Thus, the relatively small optic lobes of the Night Parrot likely reflect a decrease in optic tectum size and go hand in hand with smaller optic foramina.

A potential consequence of smaller optic foramina and optic lobes and fewer retinal ganglion cells is a decrease in visual acuity. Lower visual acuity is typically a consequence of living in scotopic (i.e., low light) environments ${ }^{35}$. In order to see effectively under scotopic conditions, the eye needs to enhance its sensitivity and this comes at the expense of visual acuity ${ }^{35}$. For example, in owls, and to a lesser extent Kakapo, a high population of photoreceptors converge on a lower number of retinal ganglion cells to improve sensitivity at the expense of acuity $^{16,36,37}$. Based on our data, we suggest that the visual acuity of the Night Parrot is lower than that of other parrots, especially the closely related Eastern Ground Parrot and other grass parakeets. Having less acute vision is unlikely to be a hindrance to Night Parrots because they prefer open habitats with few, if any trees ${ }^{1,6}$, and the risk of flying into natural obstacles is low. Lower visual acuity and flying at night could, however, increase the risk of mortality arising from anthropogenic obstacles, such as fences, that are immobile and low contrast ${ }^{38}$. This is likely one of the primary reasons that owls and other nocturnal birds frequently become entangled on barbed-wire fences $^{39-41}$. A survey of bird casualties due to barbed-wire fencing in Diamantina National Park, where Night 


\begin{tabular}{|c|c|c|c|c|c|c|c|c|c|}
\hline Species & & $\mathbf{n}$ & Specimen number & ECV & Brain SA & OLSA & OF & Orbit A & Orbit D \\
\hline Cyanoramphus auriceps & Yellow-crowned Parakeet & 1 & QMO.28238 & 2537.98 & 1726.97 & 174.54 & 3.45 & 108.05 & 10.63 \\
\hline Glossopsitta concinna & Musk Lorikeet & 1 & QMO.28231 & 3057.04 & 1443.83 & 135.66 & 3.36 & 78.82 & 11.34 \\
\hline $\begin{array}{l}\text { Glossopsitta } \\
\text { porphyrocephala }\end{array}$ & Purple-crowned Lorikeet & 1 & QMO.28574 & 1724.80 & 954.34 & 87.06 & 2.62 & 88.78 & 9.44 \\
\hline $\begin{array}{l}\text { Glossopsitta } \\
\text { pusilla }\end{array}$ & Little Lorikeet & 1 & QMO.12719 & 1537.40 & 880.31 & 97.94 & 2.19 & 80.76 & 8.97 \\
\hline Melopsittacus undulatus & Budgerigar & 1 & QMO.31840 & 1708.90 & 1053.00 & 96.75 & 2.45 & 81.18 & 9.26 \\
\hline Neopsephotus bourkii & Bourke's Parrot & 2 & QMO.28232, QMO.28399 & 1278.11 & 806.35 & 95.49 & 2.02 & 67.30 & 9.84 \\
\hline Neophema elegans & Elegant Parrot & 3 & $\begin{array}{l}\text { QMO.28276, QMO.28277, } \\
\text { QMO.28291 }\end{array}$ & 1335.60 & 838.36 & 99.32 & 2.52 & 63.12 & 10.14 \\
\hline Neophema pulchella & Turquoise Parrot & 3 & $\begin{array}{l}\text { QMO.28290, QMO.28589, } \\
\text { QMO.28296 }\end{array}$ & 1269.61 & 822.30 & 109.03 & 2.79 & 133.99 & 10.02 \\
\hline Neophema splendida & Scarlet-chested Parrot & 1 & QMO.28293 & 1285.16 & 783.46 & 92.61 & 2.12 & 81.68 & 9.68 \\
\hline Pezoporus occidentalis & Night Parrot & 1 & QMO.29055 & 2478.07 & 1212.91 & 104.25 & 2.49 & 42.96 & 11.73 \\
\hline Pezoporus wallicus & Eastern Ground Parrot & 1 & QMO.28716 & 2382.71 & 1259.38 & 149.70 & 4.77 & 76.08 & 13.06 \\
\hline Platycercus adscitus & Pale-headed Rosella & 1 & QMO.31746 & 2680.79 & 1358.34 & 137.29 & 3.84 & 100.95 & 11.58 \\
\hline Platycercus eximius & Eastern Rosella & 1 & QMO.12720 & 2696.65 & 1397.49 & 147.20 & 3.62 & 107.17 & 11.55 \\
\hline Platycercus icterotis & Western Rosella & 1 & QMO.28307 & 2389.30 & 1216.22 & 131.02 & 3.52 & 104.66 & 11.24 \\
\hline Psephotus haematonotus & Red-rumped Parrot & 1 & QMO.28294 & 1897.10 & 1056.35 & 122.53 & 3.15 & 99.10 & 10.20 \\
\hline $\begin{array}{l}\text { Psephotus } \\
\text { varius }\end{array}$ & Mulga Parrot & 1 & QMO.16667 & 1534.53 & 911.62 & 100.46 & 3.42 & 105.18 & 10.17 \\
\hline Psitteuteles versicolor & Varied Lorikeet & 1 & QMO.12024 & 1592.65 & 921.98 & 91.41 & 2.18 & 74.02 & 9.71 \\
\hline Trichoglossus chlorolepidotus & Scaly-breasted Lorikeet & 1 & QMO.32344 & 3059.63 & 1457.50 & 142.60 & 4.06 & 108.05 & 11.68 \\
\hline
\end{tabular}

Table 1. The data collected for all 18 species examined in this study, including sample sizes (n) and specimen numbers. The data columns are as follows: ECV - endocranial volume $\left(\mathrm{mm}^{3}\right)$, Brain SA - brain surface area $\left(\mathrm{mm}^{2}\right)$, OLSA - optic lobe surface area $\left(\mathrm{mm}^{2}\right)$, OF - optic foramen area $\left(\mathrm{mm}^{2}\right)$, Orbit A - orbit area $\left(\mathrm{mm}^{2}\right)$, and Orbit D - orbit depth (mm).

Parrots also occur ${ }^{42}$, revealed that at least half of the species entangled are nocturnal or active at dusk ${ }^{43}$. More importantly, a decapitated Night Parrot was also found below a stretch of barbed-wire fencing on the park ${ }^{4}$ and the species most commonly killed as a result of fence strike was the crepuscularly active Bourke's Parrot ${ }^{43}$. If we correct in our conclusion that the Night Parrot has lower visual acuity than diurnal parrots, barbed-wire fences could pose a significant hazard to the Night Parrot throughout their range ${ }^{1}$.

Although our interpretation of the Night Parrot endocast is somewhat speculative, the reduction of the optic foramina and lobes corroborates a more generalized relationship between brain morphology and nocturnality in birds. Overall, nocturnal birds have significantly smaller optic foramina than diurnal birds ${ }^{18}$. Many nocturnal birds also have relatively small optic tectum volumes ${ }^{15,16,26,44}$. Similar reductions in the optic lobes and foramina are also reported in extinct birds, such as the elephantbirds (Aepyornis spp.) ${ }^{21}$ and Hawaiian 'mole-duck' (Talpanas lippa $)^{45}$, both of which were interpreted as evidence of nocturnal behaviour. The Night Parrot adds to this generalized pattern of reduced optic foramina/nerves and optic lobes/tectum in nocturnal birds. We therefore emphasize that quantitative analyses of endocasts and cranial nerves may have significant potential in determining the activity pattern and sensory abilities of extinct and critically endangered bird species in ways that have thus far been largely overlooked.

\section{Materials and Methods}

Ethics Statement. No animals were collected for use in this study. All measurements were made from specimens housed at the Queensland Museum (see Table 1).

Specimens. To examine the anatomy of the endocast and orbits of the Night Parrot, we $\mu$ CT scanned the specimen that was found in southwest Queensland in $1990^{3}$ (Fig. 1a), the only specimen known to have an intact skull. For comparison, we scanned a total of 22 specimens representing 17 other parrot species. Within the monophyletic clade Pezoporini ${ }^{46}$, to which the Night Parrot belongs ${ }^{28}$, we examined several grass parakeets (Neophema spp.), Bourke's Parrot and the congeneric Eastern Ground Parrot. Bourke's Parrots are frequently active after sunset $^{29,30}$ and differ in vision and photoreceptor densities from exclusively diurnal parrot species ${ }^{47,48}$. The Ground Parrot shares similar terrestrial habits to the Night Parrot, but is diurnal and prefers coastal heathlands and sedgelands rather than arid interior regions $\mathrm{s}^{30,49,50}$. The other 15 species examined were selected based on availability, size and phylogenetic distribution so that we had a sufficient range of sizes to calculate allometric relationships and had species representing clades other than Pezoporini within the Psittaciformes ${ }^{46}$.

The skulls were scanned using high-resolution X-ray computed tomographic scans $(\mu \mathrm{CT})$ from a Siemens Inveon PET/CT scanner at the Centre for Advanced Imaging, University of Queensland. The resulting DICOM files were imported into Mimics (v18.0, Materialise NV) and skull 'masks' were produced through thresholding (Fig. 4). Segmenting the endocast was done slice-by-slice ensuring that foramina and fenestrae were segmented 
consistently across specimens ${ }^{51}$. A complete list of the species, specimen numbers and data are provided in Table 1. All original DICOM scans with associated acquisition parameters, as well as the surface files of cranial reconstructions and endocasts, can be found on MorphoSource (Project P453).

Measurements. 3D reconstructions of the skulls were used for measuring the surface area of the orbit, optic foramen and foramen magnum as well as the orbit depth within Mimics. All of the quantitative measurements are provided in Table 1. Orbit diameter was assessed through use of the ellipse tool. The ellipse was placed to touch the left, right, upper, and lower extremes of the orbital rim, and the surface area of the resulting (mostly circular) ellipse was determined. Similarly, the ellipse tool was used to outline the optic foramen and determine its area. Orbit depth was measured from the dorsal rim of the optic foramen to the center of the plane described by the ellipse fitted across the orbit, the same ellipse that was used to measure orbit circumference (see Figure S1 in supplementary information).

Acquiring the surface area of the optic lobes required a stepwise approach. The trigeminal nerve and blood vessel located on the surface of the optic lobe were digitally removed to avoid overestimates of optic lobe area. After this, the optic lobes were digitally dissected from the rest of the endocast and data was recorded for each side and then averaged. As the total surface area of the lobes included two sides where they had been cut from the rest of the endocast, the ellipse tool was used to measure these areas, so they could be subtracted from this total. The original left and right measurements are provided in the supplementary information (Table S1). For species represented by more than one specimen, data were averaged for analysis (Table 1).

Mesh volumes, using the "optimal resolution" setting in Mimics, were used to facilitate the dissection of the optic lobes (Figure S2 in supplementary information). The conversion of mesh volumes from voxel volumes produces slight discrepancies between the voxels and the mesh outlines, potentially leading to very small deviations of voxel-based vs. mesh-based volume estimates (Figure S2). Relative to the volumes measured, this effect is very small, identical across dissections, and does not result in distortion of the overall shape. It was therefore deemed negligible as a source of error.

Statistical analysis. We first plotted endocast volume against body mass of the Night Parrot and a large dataset of endocranial volumes of 180 other parrot species ${ }^{52}$. Body mass for the Night Parrot is the average of two specimens that were captured for a GPS tracking study ${ }^{6}$ and for other species from ${ }^{52}$. We then used a phylogeny informed statistical approach to test whether the Night Parrot deviated from allometric relationships for optic lobe surface area, optic foramen area and orbit measurements. The phylogeny was constructed from published papers $^{28,53}$ using Mesquite ${ }^{54}$ (Fig. 4). Because the phylogeny was constructed from different sources, we set all branch lengths to one. To then evaluate whether the Night Parrot differed in the relative size of the optic lobes, optic foramen, and orbits, we generated posterior probability distributions of the expected values using a Bayesian Markov Chain Monte Carlo approach across the phylogeny, following the procedures outlined in Nunn and $\mathrm{Zhu}^{55}$ and performed in $\mathrm{R}^{56}$. We ran 200,100 iterations with a burnin rate of 100 and a thin rate of 100 with endocast volume as the predictor variable to generate posterior probability distributions of 2,000 values of the predicted sizes of the optic lobes, optic foramen, and orbit dimensions of the Night Parrot.

Received: 30 October 2019; Accepted: 24 April 2020;

Published online: 09 June 2020

\section{References}

1. Olsen, P. Night Parrot: Australia's Most Elusive Bird. (CSIRO Publishing, 2018).

2. Murphy, S. A. et al. Understanding and managing the threats to Night Parrots in south-western Queensland. Emu 118, 135-145, https://doi.org/10.1080/01584197.2017.1388744 (2018).

3. Boles, W. E., Longmore, N. W. \& Thompson, M. C. A recent specimen of the night parrot Geopsittacus occidentalis. Emu 94, 37-40 (1994).

4. McDougall, A. et al. Another piece in an Australian ornithological puzzle a second Night Parrot is found dead in Queensland. Emu 109, 198-203, https://doi.org/10.1071/MU08018 (2009).

5. Murphy, S. The Night Parrot Recovery Team. Shining a light: the research unlocking the secrets of the mysterious Night Parrot. Australian Birdlife 4, 30-35 (2015).

6. Murphy, S. A., Silcock, J., Murphy, R., Reid, J. \& Austin, J. J. Movements and habitat use of the night parrot Pezoporus occidentalis in south-western Queensland. Austral Ecology 32, 858-868, https://doi.org/10.1111/aec.12508 (2017).

7. Leseberg, N. P. et al. Descriptions of known vocalisations of the night parrot Pezoporus occidentalis. Australian Field Ornithology 36, 79-88, https://doi.org/10.20938/afo36079088 (2019).

8. Murphy, S. A. et al. Observations on breeding Night Parrots (Pezoporus occidentalis) in western Queensland. Emu 117, 107-113, https://doi.org/10.1080/01584197.2017.1292404 (2017).

9. Jackett, N., Greatwich, B., Swann, G. \& Boyle, A. A nesting record and vocalisations of the Night Parrot Pezoporus occidentalis from the East Murchison, Western Australia. Australian Field Ornithology 34, 144-150, https://doi.org/10.20938/afo34144150 (2017)

10. Hall, M. I. \& Ross, C. F. Eye shape and activity pattern in birds. Journal of Zoology 271, 437-444, https://doi.org/10.1111/j.14697998.2006.00227.x (2007).

11. Wylie, D. R., Gutierrez-Ibanez, C. \& Iwaniuk, A. N. Integrating brain, behavior, and phylogeny to understand the evolution of sensory systems in birds. Frontiers in Neuroscience 9, 281, https://doi.org/10.3389/fnins.2015.00281 (2015)

12. Martin, G. R. The Sensory Ecology of Birds. 320 (Oxford University Press, 2017).

13. Corfield, J. R., Eisthen, H. L., Iwaniuk, A. N. \& Parsons, S. Anatomical specializations for enhanced olfactory sensitivity in kiwi, Apteryx mantelli. Brain, Behavior and Evolution 84, 214-226, https://doi.org/10.1159/000365564 (2014).

14. Cunningham, S. J. et al. The anatomy of the bill tip of kiwi and associated somatosensory reegions of the brain: comparisons with shorebirds. PLoS One 8, e80036, https://doi.org/10.1371/journal.pone.0080036 (2013).

15. Martin, G. R. et al. Kiwi forego vision in the guidance of their nocturnal activities. PLoS One 2, e198, https://doi.org/10.1371/journal. pone.0000198 (2007).

16. Corfield, J. R. et al. Anatomical specializations for nocturnality in a critically endangered parrot, the Kakapo (Strigops habroptilus). PLoS One 6, e22945, https://doi.org/10.1371/journal.pone.0022945 (2011).

17. Mitkus, M., Chaib, S., Lind, O. \& Kelber, A. Retinal ganglion cell topography and spatial resolution of two parrot species: budgerigar (Melopsittacus undulatus) and Bourke's parrot (Neopsephotus bourkii). Journal of Comparative Physiology A 200, 371-384, https:// doi.org/10.1007/s00359-014-0894-2 (2014). 
18. Hall, M. I., Iwaniuk, A. N. \& Gutierrez-Ibanez, C. Optic foramen morphology and activity pattern in birds. The Anatomica Record 292, 1827-1845, https://doi.org/10.1002/ar.21007 (2009).

19. Hall, M. I. The anatomical relationships between the avian eye, orbit and sclerotic ring: implications for inferring activity patterns in extinct birds. Journal of Anatomy 212, 781-794, https://doi.org/10.1111/j.1469-7580.2008.00897.x (2008).

20. Ksepka, D. T., Balanoff, A. M., Walsh, S., Revan, A. \& Ho, A. M. Y. Evolution of the brain and sensory organs in Sphenisciformes: new data from the stem penguin Paraptenodytes antarcticus. Zoological Journal of the Linnean Society 166, 202-219, https://doi. org/10.1111/j.1096-3642.2012.00835.x (2012).

21. Torres, C. R. \& Clarke, J. A. Nocturnal giants: evolution of the sensory ecology in elephant birds and other palaeognaths inferred from digital brain reconstructions. Proceedings of the Royal Society B 285, 20181540 (2018).

22. Milner, A. C. \& Walsh, S. A. Avian brain evolution: new data from Palaeogene birds (Lower Eocene) from England. Zoological Journal of the Linnean Society 155, 198-219 (2009).

23. Zelenitsky, D. K., Therrien, F., Ridgely, R. C., McGee, A. R. \& Witmer, L. M. Evolution of olfaction in non-avian theropod dinosaurs and birds. Proceedings of the Royal Society B 278, 3625-3634, https://doi.org/10.1098/rspb.2011.0238 (2011).

24. Early, C. M. Quantitative assessments of endocasts as tools for inferring neuroanatomical traits and potential functional capabilities $\mathrm{PhD}$ thesis, Ohio University, (2019).

25. Mpodozis, J., Letelier, J.-C., Concha, M. L. \& Maturana, H. Conduction velocity groups in the retino-tectal and retino-thalamic visual pathways of the pigeon (Columba livia). International Journal of Neuroscience 81, 123-136 (1995).

26. Iwaniuk, A. N., Gutierrez-Ibanez, C., Pakan, J. M. \& Wylie, D. R. Allometric scaling of the tectofugal pathway in birds. Brain, Behavior and Evolution 75, 122-137, https://doi.org/10.1159/000311729 (2010).

27. Wylie, D. R., Gutierrez-Ibanez, C., Gaede, A. H., Altshuler, D. L. \& Iwaniuk, A. N. Visual-Cerebellar Pathways and Their Roles in the Control of Avian Flight. Front Neurosci 12, 223, https://doi.org/10.3389/fnins.2018.00223 (2018).

28. Joseph, L., Toon, A., Schirtzinger, E. E. \& Wright, T. F. Molecular systematics of two enigmatic genera Psittacella and Pezoporus illuminate the ecological radiation of Australo-Papuan parrots (Aves: Psittaciformes). Molecular Phylogenetics and Evolution 59, 675-684, https://doi.org/10.1016/j.ympev.2011.03.017 (2011).

29. Fisher, C. D., Lindgren, E. \& Dawson, W. R. Drinking patterns and behavior of Australian desert birds in relation to their ecology and abundance. Condor 74, 111-136 (1972).

30. Forshaw, J. M. Australian Parrots. Illustrated by W.T. Cooper. 3rd edn, (Alexander Editions, 2002).

31. Forshaw, J. M., Fullagar, P. J. \& Harris, J. I. Specimens of the night parrot in museums throughout the world. Emu 76, 120-126 (1976).

32. Winker, K. Obtaining, preserving, and preparing bird specimens. Journal of Field Ornithology 71, 250-297 (2000).

33. Ullmann, J. F., Moore, B. A., Temple, S. E., Fernandez-Juricic, E. \& Collin, S. P. The retinal wholemount technique: a window to understanding the brain and behaviour. Brain, Behavior and Evolution 79, 26-44, https://doi.org/10.1159/000332802 (2012).

34. Iwaniuk, A. N., Heesy, C. P., Hall, M. I. \& Wylie, D. R. Relative Wulst volume is correlated with orbit orientation and binocular visual field in birds. Journal of Comparative Physiology A 194, 267-282, https://doi.org/10.1007/s00359-007-0304-0 (2008).

35. Warrant, E. J. Seeing better at night: life style, eye design and the optimum strategy of spatial and temporal summation. Vision Research 39, 1611-1630 (1999).

36. Orlowski, J., Harmening, W. \& Wagner, H. Night vision in barn owls: visual acuity and contrast sensitivity under dark adaptation. Journal of Vision 12, 1-8 (2012).

37. Fite, K. V. Anatomical and behavioral correlate of visual acuity in the great horned owl. Vision Research 13, 219-230 (1973).

38. Martin, G. R. Understanding bird collision with man-made objects: a sensory ecology approach. Ibis 153, 239-254 (2011).

39. van der Ree, R. Barbed wire fencing as a hazard for wildlife. Victorian Naturalist 116, 210-217 (1999).

40. Fitzner, R. E. Owl mortality on fences and utility lines. Raptor Research 9, 55-57 (1975).

41. Allen, G. T. \& Ramirez, P. A review of bird deaths on barbed-wire fences. Wilson Bulletin 102, 553-558 (1990).

42. Leseberg, N. P., Murphy, S. A. \& Watson, J. E. M. Automated acoustic surveys for the Night Parrot (Pezoporus occidentalis) on Diamantina National Park. (Malanda, Australia, 2019).

43. Ley, A. J. \& Tynan, B. Bird casualties in fences in Diamantina National Park, Queensland, 1996-2008. Australian Field Ornithology 25, 96-98 (2008).

44. Iwaniuk, A. N. \& Hurd, P. L. The evolution of cerebrotypes in birds. Brain, Behavior and Evolution 65, 215-230, https://doi. org/10.1159/000084313 (2005).

45. Iwaniuk, A. N., Olson, S. L. \& James, H. F. Extraordinary cranial specialization in a new genus of extinct duck (Aves: Anseriformes) from Kauai, Hawaiian Islands. Zootaxa 2296, 47-67, https://doi.org/10.5281/zenodo.191607 (2009).

46. Provost, K. L., Joseph, L. \& Smith, B. T. Resolving a phylogenetic hypothesis for parrots: implications from systematics to conservation. Emu 118, 7-21, https://doi.org/10.1080/01584197.2017.1387030 (2018).

47. Lind, O. \& Kelber, A. The intensity threshold of colour vision in two species of parrot. Journal of Experimental Biology 212, 3693-3699, https://doi.org/10.1242/jeb.035477 (2009).

48. Lind, O., Sunesson, T., Mitkus, M. \& Kelber, A. Luminance-dependence of spatial vision in budgerigars (Melopsittacus undulatus) and Bourke's parrots (Neopsephotus bourkii). Journal of Comparative Physiology A 198, 69-77, https://doi.org/10.1007/s00359-011-0689-7 (2012).

49. McFarland, D. C. The biology of the ground parrot, Pezoporus wallicus, in Queensland. I. Microhabitat use, activity cycle and diet. Wildlife Research 18, 169-184 (1991).

50. Meredith, C. W., Gilmore, A. M. \& Isles, A. C. The ground parrot (Pezoporus wallicus Kerr) in south-eastern Australia: a fire-adapted species? Australian Journal of Ecology 9, 367-380 (1984).

51. Balanoff, A. M. et al. Best practices for digitally constructing endocranial casts: examples from birds and their dinosaurian relatives. Journal of Anatomy 229, 173-190, https://doi.org/10.1111/joa.12378 (2016)

52. Iwaniuk, A. N., Dean, K. M. \& Nelson, J. E. Interspecific allometry of the brain and brain regions in parrots (Psittaciformes): comparisons with other birds and primates. Brain, Behavior and Evolution 65, 40-59, https://doi.org/10.1159/000081110 (2005).

53. Wright, T. F. et al. A multilocus molecular phylogeny of the parrots (Psittaciformes): support for a Gondwanan origin during the cretaceous. Molecular Biology and Evolution 25, 2141-2156, https://doi.org/10.1093/molbev/msn160 (2008).

54. Maddison, W. P. \& Maddison, D. R. Mesquite: a modular system for evolutionary analysis v. 3.61 (http://mesquiteproject.org, 2019).

55. Nunn, C. L. \& Zhu, L. Phylogenetic prediction to identify "evolutionary singularities" in Modern Phylogenetic Comparative Methods and Their Application in Evolutionary Biology (ed L. Z. Garamszegi) 481-514 (Springer, 2014).

56. R: A Language and Environment for Statistical Computing (2016).

\section{Acknowledgements}

The authors wish to thank Leo Joseph for discussions on Night Parrot biology and parrot phylogenetics, Cristian Gutierrez-Ibanez for statistical advice and assistance, and Laurie Ross and Duade Paton for allowing the use of their photographs. Funding for this study was provided by the Canada Research Chairs Program to ANI and Australian Research Council DE120102034 and DP170103227to VW. 


\section{Author contributions}

All authors had full access to all the data in the study and take responsibility for the integrity of the data and the accuracy of the data analysis. Study concept and design: A.N.I., V.W. Acquisition of data: A.R.K., H.J., K.M., V.W. Analysis and interpretation of the data: A.N.I., A.R.K., N.L., S.M., V.W. Drafting of the manuscript: A.N.I., A.R.K., N.L., S.M., V.W. Critical revision of the manuscript for important intellectual content: A.N.I., A.R.K., H.J., K.M., N.L., S.M., V.R. Obtained funding: A.N.I., V.W. Administrative, technical, and material support: A.N.I., H.J., K.M., V.W. Study supervision: A.N.I., V.W.

\section{Competing interests}

The authors declare no competing interests.

\section{Additional information}

Supplementary information is available for this paper at https://doi.org/10.1038/s41598-020-65156-0.

Correspondence and requests for materials should be addressed to A.N.I. or V.W.

Reprints and permissions information is available at www.nature.com/reprints.

Publisher's note Springer Nature remains neutral with regard to jurisdictional claims in published maps and institutional affiliations.

(1) Open Access This article is licensed under a Creative Commons Attribution 4.0 International License, which permits use, sharing, adaptation, distribution and reproduction in any medium or format, as long as you give appropriate credit to the original author(s) and the source, provide a link to the Creative Commons license, and indicate if changes were made. The images or other third party material in this article are included in the article's Creative Commons license, unless indicated otherwise in a credit line to the material. If material is not included in the article's Creative Commons license and your intended use is not permitted by statutory regulation or exceeds the permitted use, you will need to obtain permission directly from the copyright holder. To view a copy of this license, visit http://creativecommons.org/licenses/by/4.0/.

(c) The Author(s) 2020 